\title{
CENÁRIO PETROLÍFERO: SUA EVOLUÇÃo, PRINCIPAIS PRODUTORES E TECNOLOGIAS
}

\author{
OIL SCENERY: \\ ITS EVOLUTION, LEADING PRODUCERS AND TECHNOLOGIES
}

\author{
Marcela Taiane Schiavi ${ }^{1}$ \\ Wanda Aparecida Machado Hoffmann ${ }^{2}$
}

\begin{abstract}
RESUMO
O setor Petrolífero é um dos maiores e mais amplos mercados do mundo. E vem crescendo a cada ano, com novas tecnologias e novas perspectivas de inovação. Esta pesquisa envolve os seguintes objetivos: apresentar um breve histórico da origem do petróleo e o desenvolvimento do setor com o passar dos anos; apresentar uma análise do segmento petrolífero, indicando quais os principais países que detém as maiores reservas e as maiores empresas petrolíferas do mundo; e, uma análise de patentes apresentando o número anual de documentos de patentes na respectiva área em um determinado período, as áreas de foco tecnológico e as empresas que mais depositam documentos de patentes neste setor no Brasil. O método de pesquisa consistiu na seleção de artigos para que se tornasse possível a contextualização da história do petróleo e também na seleção de dados estatísticos que indicassem sua evolução através de tabelas e gráficos que comprovassem a produção e o desenvolvimento no decorrer dos anos. Julgou-se necessária e importante uma análise na base de dados da Derwent Innovation Index, por permitir a utilização de documentos de patentes como uma fonte de informação, visto que registram os avanços tecnológicos. Com o estabelecimento de uma estratégia de busca no período de 1994-2013 foi possível destacar a Procter \& Gamble, empresa americana, como sendo a empresa que mais deposita documentos de patentes dentro desta área no Brasil. Quanto às descobertas de reservas petrolíferas recentes tanto no Brasil quanto em outros países a tendência é de que a área se fortaleça implementando suas tecnologias, aumentando suas reservas produtivas e se destacando cada vez mais no cenário mundial.
\end{abstract}

PAlAVRAS-CHAVE: Inovação. Cenário Petrolífero. Petróleo. Patentes.

\begin{abstract}
The Petroleum sector is one of the largest and most comprehensive in the world market. And it is growing every year with new technologies and new innovation perspectives. This research involves the following objectives: to present a brief history of the origin of oil and its development over the years; to present an analysis of the oil sector, indicating the main countries which own the largest reserves and the largest oil companies in the world; and a patent analysis showing the annual number of patent documents in the respective area in a given period, the areas of technological focus and the companies that place more patent documents in this sector in Brazil. The research method consisted in the selection of articles which made it possible to put the history of oil into context and also in the selection of statistical data that would indicate it's evolution through charts and graphs that show the production and development over the years. It was deemed necessary and important to analyze the Derwent Innovation Index database, as it allowed the utilization of patent documents as a source of information, inasmuch as they register technological breakthroughs. With the establishment of a search strategy in the 19942013 period it was possible to highlight Procter \& Gamble, an American company, as the company that places more patent documents within this area in Brazil. As for the recent discoveries of oil reserves in Brazil and in
\end{abstract}

\footnotetext{
${ }^{1}$ Cursando Mestrado em Ciência, Tecnologia e Sociedade na Universidade Federal de São Carlos (2014). Graduação em Biblioteconomia e Ciência da Informação na Universidade Federal de São Carlos (2013). E-Mail: tchela_schiavi@yahoo.com.br

${ }^{2}$ Professora do Programa de Pós-Graduação em Ciência, Tecnologia e Sociedade, Professora do Departamento de Ciência da Informação e Pesquisadora do Núcleo de Informação Tecnológica em Materiais da UFSCar. Email: wanda@ufscar.br
}

Recebido em: 13/03/2015 - Aceito em: 14/05/2015 
other countries the trend is that the area be strengthened by implementing their technologies and increasing their productive reserves making them stand out more and more worldwide.

KEYWORDS: Innovation. Petroleum scenario. Oil. Patents.

\section{INTRODUÇÃO}

Em um mundo atual globalizado, a velocidade com que as mudanças tecnológicas, econômicas, políticas e sociais ocorrem é cada vez maior. Os ciclos de vida de produtos e processos vêm encurtando significativamente (GUERRANTE, 2011). Um bom indicador do ritmo dessas mudanças é o tempo necessário para que o conhecimento humano total dobre (PEIXINHO, 2003). No final do primeiro milênio, o conhecimento humano dobrou em cerca de 200 anos; no início da Revolução Industrial, foram necessários 30 anos; hoje em dia, isso ocorre a cada cinco anos (GUERRANTE, 2011).

Dentre os diversos temas de estudo abrangentes possíveis de avaliar todo o processo de mudança e crescimento tecnológico encontra-se o Petróleo que é um dos combustíveis fósseis não-renováveis mais utilizados na produção de energia, funcionamento de máquinas industriais e de veículos de transportes. Também é considerado estratégico para o futuro, o que pode ser constatado pelo uso de novas tecnologias identificadas por registros de patentes e que são adequadas para o futuro da sociedade e para o desenvolvimento sustentável.

O Brasil tem sido referência mundial em pesquisas no setor petrolífero, o que garantiu a auto-suficiência do país na produção de petróleo, anunciada no ano de 2006 (GOLDEMBERG; LUCON, 2007). O sucesso na exploração em águas profundas do mar, responsável pelo aumento na produção, deve-se aos esforços das parcerias adotadas por empresas petrolíferas com centros de pesquisa e universidades (DIRETÓRIO..., 2006).

A relevância do petróleo no sistema econômico mundial justifica a grande quantidade de inovações no setor petrolífero e a necessidade de proteção do conhecimento desenvolvido, como chave para a competitividade. Além de ser o principal combustível, o petróleo representa também importante insumo para a produção de plásticos, tecidos, tintas, entre outros materiais (DIRETÓRIO..., 2006).

O Brasil, principalmente nos últimos anos, vem implementando políticas visando fomentar o cenário da proteção intelectual e da inovação no país (ARAÚJO; et al., 2010). Ao longo desses anos, o governo aprovou a Lei de Inovação (Lei no 10.973 , de 2 de Dezembro de 2004), a qual deu origem a outras leis que visam promover o desenvolvimento de tecnologias com potencial de competição em mercados internacionais, tornando-se mais decisivo o papel da ciência, tecnologia e inovação no desenvolvimento sustentável do país. (ARAÚJO; et al., 2010).

Assim, o propósito desta pesquisa é apresentar uma contextualização da história do Petróleo desde sua origem até os dias atuais, e um panorama do desenvolvimento atual no setor petrolífero, complementando todo seu crescimento, problemas e dificuldades encontradas no processo de desenvolvimento e crescimento tecnológico, seus desafios e 
impactos na sociedade através das inovações que estão resultando em maior produtividade e maior competitividade dentre as empresas petrolíferas que buscam sempre inovar e expandir seu mercado produtivo. Apresentar quais são os principais países com maior produção petrolífera no mundo atual, quais detém as principais reservas de petróleo no mundo e quais são as empresas que mais investem em $P \& D$ no setor petrolífero mundial, e uma breve análise da área em documentos de patentes.

\section{HISTÓRIA DO PETRÓLEO}

\subsection{Petróleo no Mundo}

A palavra "petróleo" vem do latim - Petra (pedra) e Oleum (óleo). O petróleo é um composto de hidrocarbonetos em seus três estados. Contém também pequenas quantidades de compostos de enxofre, oxigênio e nitrogênio (THOMAS, 2001). Existem várias teorias sobre o surgimento do Petróleo, a mais provável é que o petróleo tenha surgido de restos orgânicos de vida aquática de animais e vegetais acumulados no fundo de lagos e mares sofrendo transformações químicas ao longo de milhares de anos, transformando-se em massas homogêneas viscosas de coloração negra, denominadas jazidas de petróleo (THOMAS, 2001). Os egípcios utilizavam esse material para embalsamar os seus mortos, os povos précolombianos utilizavam o petróleo para ser empregado na pavimentação de estradas (THOMAS, 2001).

Em 1850, na Escócia, James Young descobriu que o petróleo podia ser extraído do carvão e xisto betuminoso, e criou processos de refinação (LUSTOSA, 2002). O primeiro poço de petróleo foi descoberto nos Estados Unidos na Pensilvânia em Agosto de 1859 pelo americano Edwin Laurentine Drake (LUSTOSA, 2002). Ele foi encontrado em uma região de pequena profundidade $(21 \mathrm{~m})$, ao contrário das escavações de hoje, que ultrapassam os 6.000 metros. $\mathrm{O}$ poço revelou-se promissor e a data passou a ser considerada a do nascimento da moderna indústria petrolífera, em meados do século XIX (LUSTOSA, 2002). Com o dinheiro ganho pela descoberta Edwin Laurentine Drake tornou-se sócio de uma empresa em Wall Street especializada em petróleo. Sem nenhuma experiência para o negócio, perdeu tudo o que havia ganhado (SIMÕES, 2006).

Ainda no século XIX, o petróleo também passou a ser usado como insumo à iluminação. Em 1810, foi realizada aquela que foi considerada a primeira destilação industrial do petróleo, em Praga, obtendo-se um óleo capaz de substituir com grande vantagem os produtos até então usados para a iluminação, como o óleo de baleia e o gás de carvão. A partir do século XX, o desenvolvimento das empresas automobilísticas impulsionou, definitivamente, a indústria do petróleo. Cada vez mais, os meios de transporte terrestres, marítimos e aéreos dependiam dos combustíveis derivados de petróleo. Especialmente nos Estados Unidos, surgiram dezenas de companhias petrolíferas, que mais tarde se transformariam em poderosas organizações (IPIRANGA, 2006; THOMAS, 2001). 
A produção de óleo cru nos Estados Unidos, de dois mil barris em 1859, aumentou para aproximadamente três milhões em 1863, e para dez milhões de barris em 1874 (SOUZA, 2006). Até o final do século XIX, os Estados Unidos dominaram praticamente sozinhos o comércio mundial de petróleo, devido em grande parte à atuação do empresário John D. Rockefeller (SOUZA, 2006).

Para Penrose (1968) e Yergin (1994) apud Martins (2008), a indústria petrolífera está no centro do sistema produtivo contemporâneo, quer porque o petróleo seja (ainda) a principal fonte de energia que move a produção material, quer porque vários e muito poderosos setores industriais nela fundamentaram seu desenvolvimento, como o setor automotivo, o aeronáutico, o químico, o de materiais sintéticos, o de adubos, entre outros. A moderna indústria do petróleo teve início com a instituição da Standard Oil Company, cujo principal fundador foi John D. Rockefeller, em 1870.

De acordo com Simões (2006), Rockefeller e a Standard Oil dominaram o mercado norte americano e o nascente mercado mundial até 1909. Às vésperas da Primeira Guerra Mundial, Churchill, Primeiro Lorde do Almirantado, tomou uma decisão que transformou o petróleo em uma mercadoria estratégica, convertendo a frota inglesa, a principal máquina de guerra do mundo, do carvão ao petróleo. A alteração tinha várias vantagens, dentre elas diminuindo em $30 \%$ a carga de combustível necessária para mover os navios (SIMÕES, 2006).

Simões (2006) ainda diz que, após estabelecer seu uso generalizado, com a popularização dos veículos à explosão, o petróleo passou a confirmar seu status de principal "commodity" estratégica mundial. Pela mobilidade do óleo, pelo fato de os mercados consumidores estarem distantes dos centros produtores, pela atuação de companhias estrangeiras transnacionais, o petróleo passou a ser comercializado em um mercado mundial. Seu preço passou a ter cotação nas principais bolsas de valores e carregamentos fora de contratos de longo prazo passaram a ser negociáveis no chamado mercado "spot". ${ }^{3}$

No mercado, o petróleo passou a avançar cada vez mais trazendo no entanto junto com o crescimento as crises, principalmente relacionadas aos picos de alta de seu preço. $\mathrm{O}$ petróleo, que já era importante para o crescimento mundial, tornou-se mais importante com o passar dos anos gerando com esse crescimento novas tecnologias, tanto na extração quanto no processo de produção e desenvolvimento, novos locais de descobertas e novas etapas.

Nos anos de 1973 e 1974 o petróleo teve um aumento relativo de $400 \%$ em seu preço, causando reflexos intensos nos Estados Unidos e na Europa e desestabilizando a economia por todo o mundo (GASPARETTO JUNIOR, 2014). Em 1979, houve o segundo choque do petróleo, que paralisou a produção no Irã, pressionando o preço do barril de óleo que teve um grande aumento na época. Nos anos de 1990 e 1991, o Iraque invadiu o Kwait e por isso, tornou-se alvo de uma ofensiva militar comandada pelos Estados Unidos, gerando incertezas

\footnotetext{
${ }^{3}$ Mercado "spot": mercado do produto acabado para venda e com pronta disposição de entrega (ABITANTE, 2008).
} 
sobre a produção na região e pressionando o preço do barril durante a assim chamada Guerra do Golfo (LUSTOSA, 2002).

Nos anos seguintes houve uma grande tensão em países do Oriente Médio, a chamada Primavera Árabe que gerou incertezas sobre a produção de petróleo na região e pressionou o preço do barril de óleo que sofreu nova alta (SOUZA, 2006). Nos anos de 80 e 90, os avanços tecnológicos reduziram os custos de exploração e produção, criando um novo ciclo econômico para a indústria petrolífera. As reservas mundiais provadas, em 1996, eram 60\% maiores que no ano de 1980(THOMAS, 2001).

O petróleo foi se impondo como fonte de energia e atualmente, com o advento da petroquímica, além da ampla utilização de seus derivados, centenas de novos produtos são produzidos diariamente. Assim o petróleo passou a ser imprescindível às facilidades e comodidades da vida moderna (THOMAS, 2001).

\subsection{Petróleo no Brasil}

No Brasil, pode-se dizer que a história do petróleo teve início no ano de 1892. Neste ano, o fazendeiro Eugênio Ferreira de Camargo perfurou o primeiro poço em busca de petróleo em sua fazenda na cidade de Bofete (interior do estado de São Paulo). Porém, o poço de 488 metros de profundidade teve como resultado apenas água sulfurosa. Foi a primeira tentativa de se encontrar petróleo em território brasileiro. Apenas no ano de 1939 foi descoberta a primeira jazida de petróleo explorável comercialmente em território brasileiro na cidade de Salvador (BA) no bairro de Lobato (LUSTOSA, 2002).

Em abril de 1938, diante da importância que o setor de petróleo ganhava na estrutura econômica e na opinião pública do País, o presidente Getúlio Vargas criou o Conselho Nacional do Petróleo (CNP) (MARTINS, 2008). O Conselho surgia com a missão de controlar e supervisionar a produção e o comércio de derivados de petróleo no país e, para isso, determinou que a partir daquela data, por se tratar de um insumo estratégico, apenas brasileiros natos poderiam ser sócios da Refinaria denominada Ipiranga S.A. Companhia Brasileira de Petróleos (MARTINS, 2008).

Novas prospecções governamentais saíram em busca de outros campos de petróleo ao longo do território brasileiro. No ano de 1941, o governo brasileiro anunciou o estabelecimento do campo de exploração petrolífera de Candeias no Estado da Bahia. Apesar das descobertas em pequena escala, o surgimento dessa nova riqueza incentivou, em 1953, a oficialização do monopólio estatal sobre a atividade petrolífera e a criação da empresa estatal “Petróleo Brasileiro S.A.”, mais conhecida como Petrobras (MARTINS, 2008).

Em Outubro de 1953, o presidente Getúlio Vargas sancionou a Lei 2004, que estabeleceu o monopólio estatal de pesquisa, refino e transporte do petróleo, que não seria nada mais do que a exploração petrolífera no Brasil em prol da União, instituindo com isso a Petrobras como sendo uma empresa estatal de economia mista, de capital aberto e sendo o governo brasileiro o acionista majoritário (GASPARETTO JUNIOR, 2014). 
Na década de 1960, novas medidas ampliaram o grau de atuação da Petrobras na economia brasileira. No ano de 1968, a empresa passou a desenvolver um projeto de extração, iniciando a exploração de petróleo em águas profundas. Após as primeiras descobertas, outras prospecções ampliaram significativamente a produção petrolífera brasileira. Sendo assim, o petróleo passou a ser uma das principais "commodities" minerais produzidas pelo Brasil e comercializadas mundialmente (LUSTOSA, 2002; THOMAS, 2001).

No ano de 1975, houve o lançamento do Proálcool (Programa Brasileiro de Álcool), criado para substituir em larga escala o uso de derivados do petróleo devido à alta no preço do barril. No ano de 1974 foi descoberto petróleo na Bacia de Campos, mas o início da exploração se deu no ano de 1977, com a entrada em operação do Campo Enchova, produzindo petróleo a 120 metros de profundidade, considerada grande para a época (LUSTOSA, 2002; SOUZA, 2006).

Em 1982, pela primeira vez um evento no Rio de Janeiro reuniu empresas que apresentaram seus produtos e serviços. Ao longo dos anos eventos dessa natureza ajudaram a consolidar o Rio de Janeiro como a "Capital Nacional do Petróleo", com o estado sendo responsável por mais de $70 \%$ de todo o óleo produzido no país. Dois anos mais tarde, em 1984, e dez anos após a descoberta de petróleo na Bacia de Campos (RJ), é encontrado o primeiro campo gigante do país, o Albacora, fazendo com que o Brasil alcançasse a marca de 500 mil barris de óleo produzidos por dia (LUSTOSA, 2002).

No ano de 1989 a produção de álcool caiu de 11,8 milhões de toneladas para 7,3 milhões de toneladas, gerando assim a crise do Proálcool. O governo adotou medidas para evitar o desabastecimento da frota, aumentando as importações e adicionando metanol ao combustível. Em 1997, no Brasil, houve o fim do monopólio do petróleo, com a promulgação da Lei do Petróleo, que flexibilizou o monopólio estatal do petróleo, criou o Conselho Nacional de Política Energética (CNPE) e a Agência Nacional do Petróleo (ANP). O CNPE e a ANP tornaram-se responsáveis pelas concessões de blocos exploratórios dando ao Brasil seu primeiro grande passo ao ingressar no Ranking do grupo dos 16 países do mundo que produzem mais de um milhão de barris de óleo por dia (LUSTOSA, 2002).

Em 1999 a ANP realiza o primeiro leilão de blocos exploratórios no país. No ano seguinte, 2000, a Petrobras produziu petróleo a 1.877 metros de profundidade, no Campo de Roncador, um recorde mundial (THOMAS, 2001).

No ano de 2005, em Santos, foram encontrados os primeiros indícios de petróleo na camada pré-sal. A conclusão das análises em um segundo poço indicou volumes recuperáveis entre cinco e oito bilhões de barris de petróleo e gás natural. Com essas grandes descobertas e com o avanço ano após ano da Petrobras e suas novas descobertas, o Brasil, em 2006, atingiu a autossuficiência na produção de petróleo. O fato foi comemorado como um ato de "independência" pelo governo brasileiro (SOUZA, 2006). 
Em 2008, o navio-plataforma P-34 extraiu óleo da camada pré-sal pela primeira vez, no campo de Jubarte, na bacia de Campos. Em maio de 2009, começou a produção no campo do Tupi, os preços internacionais atingiram patamares recordes e especialistas creditaram o aumento à demanda de países como Índia e China (PETROBRAS, 2013a).

De acordo com Epstein (2014), uma queda na demanda pressionaria a supremacia do petróleo na medida em que aumentasse o uso de combustíveis alternativos, como o gás natural. $\mathrm{O}$ autor afirma que fontes não convencionais de petróleo estão sendo exploradas em países como a Índia, Bahrein e Uganda. Do lado da demanda, um terço da frota de automóveis no Brasil já pode rodar com combustível alternativo. As constantes modificações, atualmente, em decorrência dos avanços tecnológicos são estabelecidas e apresentadas por diversas empresas, indústrias, centros de pesquisas e instituições de ensino, a par de grandes desenvolvimentos na área de extração, produção e desenvolvimento. A extração, por exemplo, era feita por bombeio mecânico, também conhecido como "cavalo-de-pau", usado durante mais de um século para extrair o petróleo da terra e também tinha um alto custo de manutenção. Hoje utilizam-se motores lineares para extração, uma tecnologia muito empregada pela Petrobras, já que é ela que detém a patente da aplicação da tecnologia (THOMAS, 2001). De acordo com Gouveia (2014, p. 3), "atualmente, a geofísica é capaz de oferecer novas tecnologias e de melhorar o imageamento dos dados em profundidade, com fontes acústicas de maior potência, coletas repetitivas (4D) e técnicas wide azimuth para melhorar a resolução do sinal sísmico em reservatórios".

Essas e outras tecnologias vêm ganhando força e destaque na área petrolífera, com o intuito de melhorar os processos de extração, produção e desenvolvimento petrolífero, diminuindo os custos de produção e de desenvolvimento desta área, gerando maior emprego de automação, maior competitividade, e assim maior agilidade nos processos de produção e exportação.

\subsection{Patentes como fonte de informação}

O avanço da ciência e tecnologia tem colaborado positivamente para o crescimento e desenvolvimento tecnológico dos países. Até meados do ano de 1960 pouco se ouvia falar sobre estudos acerca de tecnologia mas, no entanto, economistas sempre reconheceram a importância das inovações para a expansão da produtividade e da performance competitiva mundial (ORTIZ NETO; COSTA, 2007). As invenções e inovações somente adquirem importância econômica em função de sua introdução e ampla difusão no mercado (ROSENBERG, 1982, p. 96).

Com o passar dos anos o interesse em estudos voltados ao conhecimento tecnológico foi intensificado e, com isto, surge a necessidade de proteção. Segundo Bell et al. (1984, p.1), "os setores industriais tornaram-se um dos principais elementos impulsionadores das taxas de crescimento entre países desenvolvidos e em desenvolvimento". De acordo com o autor, quando avanços tecnológicos são empreendidos por países ainda em desenvolvimento, em 
uma magnitude que permita estabelecer vantagens competitivas, haverá sempre uma tendência de convergência para com os países já desenvolvidos.

Nas últimas décadas a inovação e o desenvolvimento tecnológico vêm mostrando-se promissores, principalmente para empresas e indústrias. A pesquisa e desenvolvimento de novos produtos e processos, muitas vezes requerem altos investimentos e uma diferenciação na qualidade de seus serviços. No entanto, é de suma importância que as organizações busquem meios de proteção para seus investimentos com o intuito de obter a longo prazo um retorno de seu esforço e também proteger-se de competidores ativos no mercado.

A patente é um meio de proteção legal e valioso para quem busca proteger seus inventos. O prazo de vigência permite ao titular o direito de exclusividade de fabricação, comercialização, entre outros, da matéria protegida. De acordo com a Lei da Propriedade Industrial brasileira (BRASIL, 1996, p. 1), a patente é:

um título de propriedade temporária sobre uma invenção dado a atores ou outras pessoas físicas ou jurídicas detentoras de direitos sobre criação. Em contrapartida, o inventor se obriga a revelar detalhadamente todo o conteúdo técnico da matéria protegida pela patente.

O documento de patentes é fundamental para orientar as atividades de pesquisa, poupar tempo e evitar gastos desnecessários, a busca de informação em documento de patentes é essencial (INSTITUTO..., 2014). Quase todas as informações contidas no documento de patente não está disponível em outras fontes de informações, no entanto, muitos especialistas desconhecem as invenções de empresas da sua área por não buscarem informações neste tipo de documento.

A patente conta também com informações detalhadas sobre tecnologia, inventos, mercados, etc., e com classificações específicas de cada área de acordo com a Classificação Internacional de Patentes (CIP), que está em vigor desde 1968, e é usada em mais de 90 países (INSTITUTO..., 2014).

A análise de patentes é vista como uma ajuda valiosa para diversas áreas do conhecimento. Através da análise de patentes é possível obter resultados de inovações tecnológicas, atividades competitivas, tendências tecnológicas futuras. Neste contexto, notase que cada vez mais empresas investem na criação de tecnologias, com o intuito de melhorar seu produto. No entanto, para orientar as atividades de pesquisa, poupar tempo e evitar gastos desnecessários, a busca de informação em documento de patentes é fundamental (INSTITUTO..., 2014). Segundo Nijhof (2007), com o avanço tecnológico, com as ferramentas de busca em bases de dados e com a grande quantidade de informação disponível para consulta, a busca deve ser cautelosa ao definir o escopo e a estratégia para recuperar as informações adequadas para o foco de pesquisa.

\subsection{O cenário petrolífero, seus principais produtores e investimentos}


A evolução do cenário petrolífero pode ser analisada através das tecnologias que foram desenvolvidas durante décadas para agilizar o processo de extração, refino e produção de petróleo, assim como a criação de diversas empresas que competem entre si em busca de melhorias e mais qualidade neste cenário. Com isto, o petróleo tornou-se a principal fonte de energia que move a produção material (PENROSE, 1968; Yergin, 1994 apud MARTINS, 2008).

Uma boa maneira de avaliar e aplicar métodos voltados a gerar resultados com o propósito de fundamentar o estudo desenvolvido é a utilização de indicadores gerados através de dados utilizados no texto com base na bibliometria ${ }^{4}$ aplicada e a utilização de publicações científicas na área petrolífera que teve como propósito fundamentar o estudo teórico e a execução da pesquisa.

Os indicadores podem ser compreendidos como parâmetros que fornecem indicações ou descrições sobre o estado de um fenômeno (OCDE, 2002). Desde o aparecimento da estatística como ciência, os indicadores têm sido importantes para o entendimento de sistemas complexos, pelo fato de representarem um compromisso entre a busca pela exatidão científica, proporcionada pelo cálculo matemático, e a informação concisa e clara (OCDE, 2002). Entretanto, segundo Santos e Kobashi (2005, p. 5) "[...] os indicadores quantitativos não representam uma 'verdade' sobre o estado da ciência e da tecnologia, mas são aproximações da realidade ou uma expressão incompleta dela".

Através do grande avanço das inovações tecnológicas, é possível identificar os países que são os maiores produtores de petróleo do mundo e identificar os novos produtos e máquinas que facilitam a produção e o desempenho de empresas dentro do mercado.

Um estudo elaborado pela revista Forbes junto com a Wood Mackenzie em 2013, mostrou que a média de volume de petróleo e gás natural produzido pelas empresas no ano de 2003 era de 3.4 milhões de barris por dia. Em 2013 este número aumentou para mais de 4 milhões por dia (BEZERRA, 2013).

Em 2014, a Forbes (BARBOSA, 2014) divulgou um "ranking" com as 10 maiores empresas petrolíferas do mundo, com base na receita, lucro, ativos e valor de mercado das empresas. Neste, a Petrobras aparece na nona colocação, ou seja, subiu sete posições em comparação com o "ranking" da Forbes publicado em 2011. A empresa que lidera o "ranking" é a empresa americana Exxon Mobil, uma empresa multinacional de petróleo e gás dos Estados Unidos com filiais em diversos países. A revista mostra o quanto essas empresas lucram, suas receitas e quais seus valores de mercado (Tabela 1).

TABELA 1. As 10 maiores empresas Petrolíferas do mundo e seus resultados financeiros em 2014.

\footnotetext{
4 A bibliometria pode ser definida como sendo uma contagem de artigos científicos, patentes e citações. Dependendo da finalidade do estudo, podem ser considerados como dados tanto o texto que compõe a publicação como os elementos presentes em registros sobre publicações extraídos de bases de dados bibliográficas, como nomes dos autores, título, fonte, idioma, palavras-chave, classificações e citações (RAO, 1986 ; ZHU; et al, 1999).
} 


\begin{tabular}{|c|c|c|c|c|}
\hline Empresa & País de origem & Receita (dólares) & Lucro & Valor de Mercado \\
\hline $\mathbf{1}^{\mathbf{0}}$ Exxon Mobil & Estados Unidos & US\$ 394 bilhões & US\$32,6 bilhões & US\$ 422,3 bilhões \\
\hline $\mathbf{2}^{\mathbf{0}}$ PetroChina & China & US $\$ 328,5$ bilhões & US $\$ 21,1$ bilhões & US\$ 202 bilhões \\
\hline $\begin{array}{c}3^{\mathbf{o}} \text { Royal Dutch } \\
\text { Shell }\end{array}$ & $\begin{array}{l}\text { Reino Unido e } \\
\text { Holanda }\end{array}$ & US $\$ 451,4$ bilhões & US $\$ 16,4$ bilhões & US\$ 234,1 bilhões \\
\hline $4^{\circ} \mathrm{BP}$ & Reino Unido & US $\$ 379,2$ bilhões & US $\$ 23,6$ bilhões & US $\$ 148,8$ bilhões \\
\hline $\mathbf{5}^{\mathbf{0}}$ Chevron & Estados Unidos & US $\$ 211,8$ bilhões & US $\$ 21,4$ bilhões & US\$ 227,2 bilhões \\
\hline $\mathbf{6}^{\mathbf{0}}$ Gazprom & Rússia & US $\$ 164,6$ bilhões & US\$ 39 bilhões & US $\$ 88,8$ bilhões \\
\hline $\mathbf{7}^{\mathbf{0}}$ Total & França & US $\$ 227,9$ bilhões & US $\$ 11,2$ bilhões & US $\$ 149,8$ bilhões \\
\hline $8^{\circ}$ Sinopec & China & US $\$ 445,3$ bilhões & US $\$ 10,9$ bilhões & US\$ 94,7 bilhões \\
\hline $9^{\circ}$ Petrobras & Brasil & US $\$ 141,2$ bilhões & US\$10,9 bilhões & US\$ 86,9 bilhões \\
\hline $\mathbf{1 0}^{\mathbf{o}}$ Rosneft & Rússia & US $\$ 142,6$ bilhões & US $\$ 12,8$ bilhões & US\$ 70 bilhões \\
\hline
\end{tabular}

Fonte: Síntese da pesquisa da revista Forbes publicada na Exame.com em 08 Maio.2014 (BARBOSA, 2014).

A Petrobras, empresa brasileira, que não constava na lista até o ano 2003, em 2014 ocupa o nono lugar, com valor de mercado de 86,9 bilhões. No entanto, com as recentes crises envolvendo a estatal brasileira, sua colocação neste "ranking" tende a cair. Assim, pode-se dizer que muito deste valor de mercado da Petrobras vem em consequência de sua auto-suficiência atingida no ano de 2006 e pela descoberta da camada do pré-sal (BARBOSA, 2012).

A Tabela 2 apresenta um "ranking" dos quinze países com maior reserva de petróleo do mundo de acordo com o relatório estatístico anual de energia mundial da companhia BP, empresa multinacional sediada no Reino Unido que opera no setor de energia, principalmente na área de petróleo e gás (BARBOSA, 2012). O relatório apresenta o crescimento dos países em 20 anos (1991 a 2011) e também a quantia de reservas provadas em bilhões que cada empresa obteve nesse período.

TABELA 2. Países com maiores reservas de petróleo do mundo.

\begin{tabular}{cccccc}
\hline \multirow{2}{*}{ Colocação } & País & $\begin{array}{c}\text { Participação } \\
\text { Mundial (\%) }\end{array}$ & $\begin{array}{c}\text { Reservas } \\
\text { provadas em } \\
2011 \text { (bilhões) }\end{array}$ & $\begin{array}{c}\text { Reservas } \\
\text { provadas em } \\
1991 \text { (bilhões) }\end{array}$ & $\begin{array}{c}\text { Crescimento em } \\
20 \text { anos }(\%)\end{array}$ \\
$1^{\circ}$ & Venezuela & 17,9 & 296,5 & 62,6 & 373 \\
$2^{\circ}$ & Arábia Saudita & 16,1 & 265,4 & 260,9 & 1,7 \\
$3^{\circ}$ & Canadá & 10,6 & 175,2 & 40,1 & 337 \\
$4^{\circ}$ & Irã & 9,1 & 151,2 & 92,9 & 62,8 \\
\hline
\end{tabular}




\begin{tabular}{|c|c|c|c|c|c|}
\hline $5^{\circ}$ & Iraque & 8,7 & 143,1 & 100 & 43,1 \\
\hline $6^{\circ}$ & Kuwait & 6,1 & 101,5 & 96,5 & 5,2 \\
\hline $7^{\circ}$ & $\begin{array}{c}\text { Emirados } \\
\text { Árabes Unidos }\end{array}$ & 5,9 & 97,8 & 98,1 & 0,3 \\
\hline $8^{\circ}$ & Rússia & 5,3 & 88,2 & não informado & 20,8 \\
\hline $9^{\circ}$ & Líbia & 2,9 & 47,1 & 22,8 & 106,6 \\
\hline $10^{\circ}$ & Nigéria & 2,3 & 37,2 & 20 & $86 \%$ \\
\hline $11^{\circ}$ & $\begin{array}{l}\text { Estados } \\
\text { Unidos }\end{array}$ & 1,9 & 30,9 & 32,1 & $\begin{array}{c}\text { Queda em } 20 \text { anos } \\
\text { de } 4 \%\end{array}$ \\
\hline $12^{\circ}$ & Cazaquistão & 1,8 & 30 & não informado & 455 \\
\hline $13^{\circ}$ & Catar & 1,5 & 24,7 & 3 & 723 \\
\hline $14^{\circ}$ & Brasil & 0,9 & 15,1 & 4,8 & 214,6 \\
\hline $15^{\circ}$ & China & 0,9 & 14,7 & 15,5 & $\begin{array}{c}\text { Queda em } 20 \text { anos } \\
\text { de } 5,2 \%\end{array}$ \\
\hline
\end{tabular}

Fonte: Barbosa, 2012.

Através da Tabela 2 é possível analisar o crescimento dos países nos últimos vinte anos. Alguns países como Estados Unidos e China tiveram uma pequena queda no ranking. $\mathrm{O}$ Brasil encontra-se na décima quarta posição com boas perspectivas de entrar na lista das dez maiores potências mundiais do petróleo como consequência da descoberta do pré-sal. Entretanto, em 2013 o Brasil passou à $15^{\mathrm{a}}$ posição e a China assumiu a $14^{\mathrm{a}}$ posição, com 1,0\% da participação mundial (OPEC, 2013).

Os investimentos de empresas como a Petrobras, empresa estatal brasileira mais rentável para o mercado no país, em novas tecnologias e em inovação, e em relação à distribuição de derivados de petróleo, também é importante pela participação no setor elétrico brasileiro. A Petrobras está presente em 17 países, onde, segundo o relatório anual de sustentabilidade da Petrobras (PETROBRAS, 2013b) investiu-se R \$ 5,1 bilhões, 90\% dos quais foram aplicados em exploração e produção de óleo e gás natural na América Latina, África e nos Estados Unidos. Aqui no Brasil, ela conta com o serviço de fontes renováveis, como o biodiesel, comercialização e a produção do etanol (PETROBRAS, 2013b).

A Figura 1 mostra os investimentos realizados pela Petrobras no ano de 2013 nas áreas de Exploração e Produção, Abastecimento, Gás e Energia, no mercado Internacional, na Distribuição, nos Biocombustíveis e nos investimentos Corporativos. 


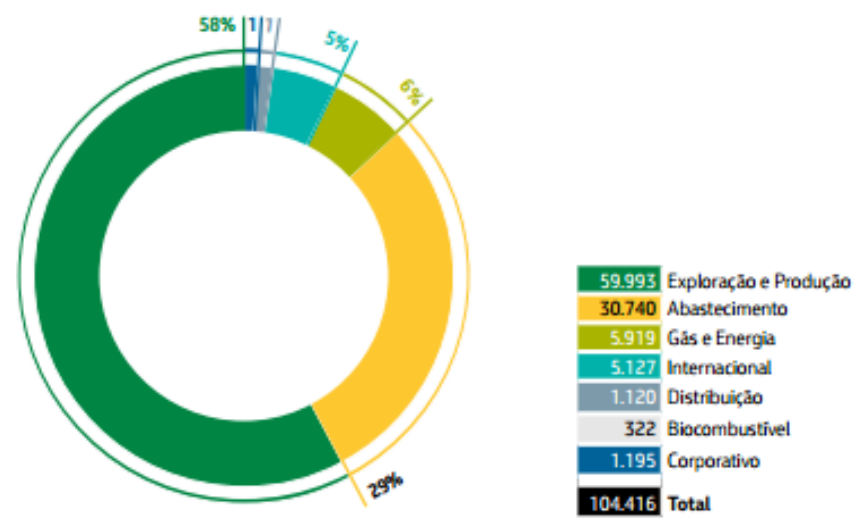

FIGURA 1. Investimentos da empresa Petrobras no ano de 2013.

Fonte: Petrobras, 2013a

As atividades de Exploração e Produção representam o campo com maior índice de investimento da empresa estatal Petrobras, seguido pelo campo de abastecimento em segundo lugar. Uma das causas que levaram a esse alto índice de investimento dentro da área de Exploração e Produção foi o foco no desenvolvimento da produção dos campos do pré-sal e do pós-sal. $\mathrm{Na}$ área de abastecimento a maior parte dos recursos investidos foram aplicados na ampliação de parques de refino da empresa (Petrobras, 2013b).

A Figura 2 apresenta o gráfico de despesas na área de $P \& D$ nas grandes empresas que estão voltadas ao ramo de petróleo.

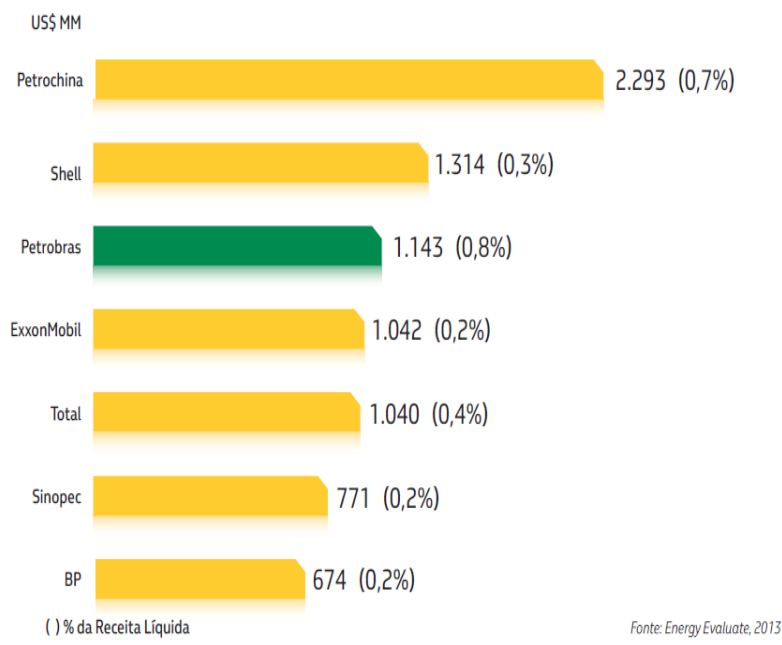

FIGURA 2. Despesas em P\&D no ano de 2012 das empresas de energia do mundo.

Fonte: Petrobras, 2013a.

Observa-se na Figura 2 que a empresa com maior investimento nesta área é uma empresa da China. A Petrobras encontra-se em terceiro lugar nas empresas com maior gasto em $\mathrm{P} \& \mathrm{D}$ do mundo. Nota-se que as empresas investem bastante em $\mathrm{P} \& \mathrm{D}$, porém quando avaliados em porcentagem da sua receita líquida vê-se que este número é pequeno em relação a outros investimentos e gastos dessas empresas. 
O preço do petróleo exerce papel decisivo na evolução das atividades dos mercados econômicos. Em primeiro lugar, o preço do petróleo tem impacto sobre o conjunto das atividades para as quais não pode ser substituído. Em segundo lugar, a evolução de seu preço viabiliza ou não a oferta de fontes energéticas que possam substituí-lo. Mas essa dinâmica deve ser sustentável. Movimentos de curto prazo podem ter grande impacto, mas não são suficientes para desenvolver novas áreas de produção ou consolidar alternativas energéticas ao petróleo (FUNDAÇÃO..., 2012).

As empresas estatais de petróleo controlam a maior parte das reservas e a maior parte do volume de produção oferecido no mercado internacional. A atividade dessas empresas, porém, não segue necessariamente a racionalidade empresarial ou práticas comerciais que maximizem os fluxos de receita porque, controladas pelos governos, atendem mandatos governamentais e objetivos políticos de curto prazo, que incluem subsídios, políticas regionais, programas de assistência social, entre outros (FUNDAÇÃO..., 2012).

Com a descoberta do pré-sal, abre-se para o Brasil um novo caminho no mercado petrolífero, apresentando perspectivas promissoras e de destaque entre outros países, deixando-o mais perto de ser uma grande potência energética.

\section{METODOLOGIA}

A metodologia para a realização da presente pesquisa pode ser considerada descritiva, pois foram utilizados procedimentos específicos com a finalidade de fundamentar a base teórica aqui apresentada. A abordagem também é quantitativa, pois a pesquisa volta-se em uma análise de informações de indicadores de documentos de patentes na área do petróleo, elaborados estatisticamente por bibliometria. Desse modo, a análise consistiu em um levantamento bibliométrico do número de documentos de patentes depositadas no Brasil no decorrer dos anos. Com base em publicações científicas e documentos que apresentassem um bom contexto histórico, são apresentados dados de empresas, como quantidade de produção de barris, empresas e países com maiores reservas mundiais e despesas de pesquisa e desenvolvimento $(\mathrm{P} \& \mathrm{D})$.

O processo de análise dos dados bibliométricos dos documentos de patentes constituiu-se a partir de uma busca realizada na base de dados da Derwent Innovation Index, que conta com a maior e mais abrangente base de dados de documentos de patentes. A Derwent Innovation Index é uma base de dados muito bem conceituada no mundo. A elaboração, análise dos indicadores de patentes e os documentos recuperados na busca foram restritos ao período de 1994-2013. Por meio dessa busca foi possível coletar uma amostra de 24.578 documentos de patentes, dentre os quais analisou-se um total de 18.188 documentos de patentes referentes ao período estabelecido. Nos anos de 2012 e 2013 há uma pequena quantidade de documentos de patentes disponíveis, devido aos 18 meses de sigilo, que é o período de confidencialidade e também em consequência do atraso entre as publicações de dados de patentes no escritório de patentes e sua inserção, processamento e publicação na base de dados. 
A escolha das palavras-chave para a elaboração da busca na base de dados foi realizada através do uso de termos relacionados à área de Petróleo e também através de uma busca exaustiva relacionada ao Código de Classificação Internacional de Patente. Os termos finais para a busca na base de dados da Derwent Innovation Index foram definidos conforme apresentados na Tabela 3.

TABELA 3. Palavras-chave e códigos de classificação internacional de patentes para a busca na Derwent Innovation Index.

\begin{tabular}{c|c|c|c}
\hline $\begin{array}{c}\text { Palavras- } \\
\text { chave }\end{array}$ & Código de Classificação Internacional de Patentes & Data & $\begin{array}{c}\mathbf{N}^{\mathbf{o}} \text { Doc. } \\
\text { Pat. }\end{array}$ \\
\hline & A47J-036/26 OR A62C-003/06 OR C08F-240/00 OR C10G-073/02 OR & & \\
C10G-073/36 OR C10G-073/38 OR C10G-073/42 OR C10G-099/00 OR & & \\
Petroleum & C10L OR C10L-003/00 OR C10L-003/12 OR C10M-101/02 OR C10M- & 29 Nov. & 24.578 \\
OR Oil & $121 / 02$ OR C10M-159/04 OR C12Q-001/64 OR C12S-001/00 OR C14B- & 2014 & \\
& $099 / 00$ OR D01F-009/155 OR C10L 1/32 OR C10M 105/02 OR C10M & & \\
& $115 / 02$ OR C10M 127/00 OR C10M 171/00 & & \\
\hline
\end{tabular}

Fonte: Elaborado pela autora

A partir dos resultados da busca foi possível analisar, através de indicadores, a quantidade de documentos depositados, empresas e as áreas de domínio tecnológico no Brasil.

\section{RESULTADOS E DISCUSSÕES}

As informações que podem ser extraídas dos documentos de patentes disponibilizados através da base de dados da Derwent Innovation Index, incluem o número de documentos de patentes, as empresas que depositam patentes no Brasil e quais as áreas de domínio tecnológico. A Figura 3 mostra o número anual de patentes depositadas no Brasil na área Petrolífera no período de 1994 a 2013. 


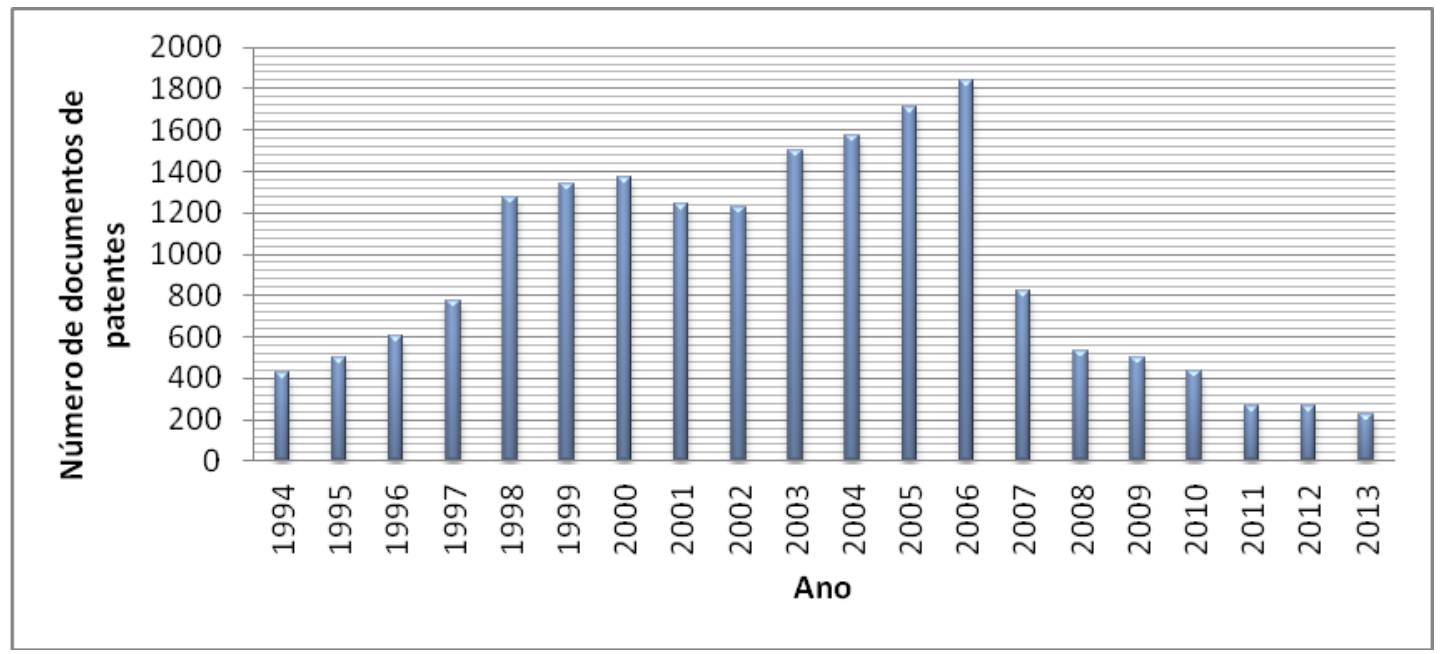

FIGURA 3. Número anual de documentos de patentes na área petrolífera para o período de 1994-2003.

Fonte: Elaborado pela autora

Observa-se que na Figura 3 o número de documentos de patentes depositados na primeira década do período pesquisado foi crescente. A partir dos anos de 2003 e 2004 notase um crescimento considerável e contínuo no número de depósito de patentes. No entanto, o pico maior ocorreu no ano de 2006, tendo como um dos prováveis motivos de alta neste período o fato do Brasil atingir sua autossuficiência na produção de petróleo. Ressalta-se que a queda constante apresentada após o ano de 2007 possivelmente deve ser atribuída à descoberta da camada do Pré-Sal, onde todo o foco das indústrias no Brasil voltou-se a pesquisas e investimentos nessa nova área. Entretanto, leva-se ainda em consideração fatores como tempo de segredo (18 meses) e, consequentemente, "atraso" de indexação dos registros dessas patentes na base de dados.

Uma visão sobre as Áreas de Foco Tecnológico no setor petrolífero é apresentada na Figura 4.

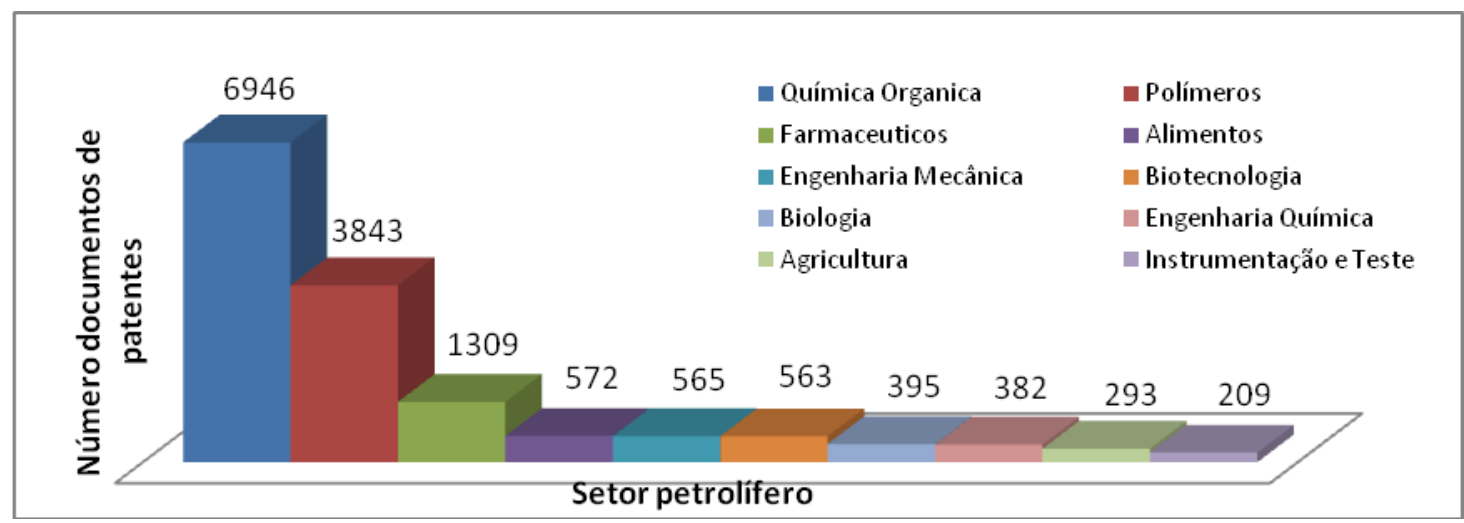

FIGURA 4. Áreas de Foco Tecnológico no setor petrolífero.

Fonte: Elaborado pela autora

Observa-se na Figura 4 que a área de Química Orgânica é a área que contém o maior número de registros de documentos de patentes, isto é, trata-se da área que envolve principalmente os processos de aplicações do petróleo. A química orgânica é uma área 
importante, onde ocorrem processos como separação, conversão e tratamento do petróleo, sendo uma das principais áreas relacionadas aos derivados de petróleo. Nota-se que a área de Polímeros também possui muitos registros de patentes, pois a principal matéria-prima para a produção de polímeros é o petróleo. A utilização do petróleo em áreas como Farmacêuticos, Alimentação, Engenharia Mecânica, Biotecnologia, Biologia, entre outros apresentados na figura, são áreas que utilizam os derivados do petróleo para processos e produtos úteis em indústrias e institutos de pesquisas. Ressalta-se que não foram analisados períodos, uma vez que a intenção foi apresentar apenas as áreas de foco tecnológico que contemplam os maiores números de documentos de patentes.

A Figura 5 apresenta as empresas que mais depositaram documentos de patentes no período de 1994-2013 dentro da área de petróleo.

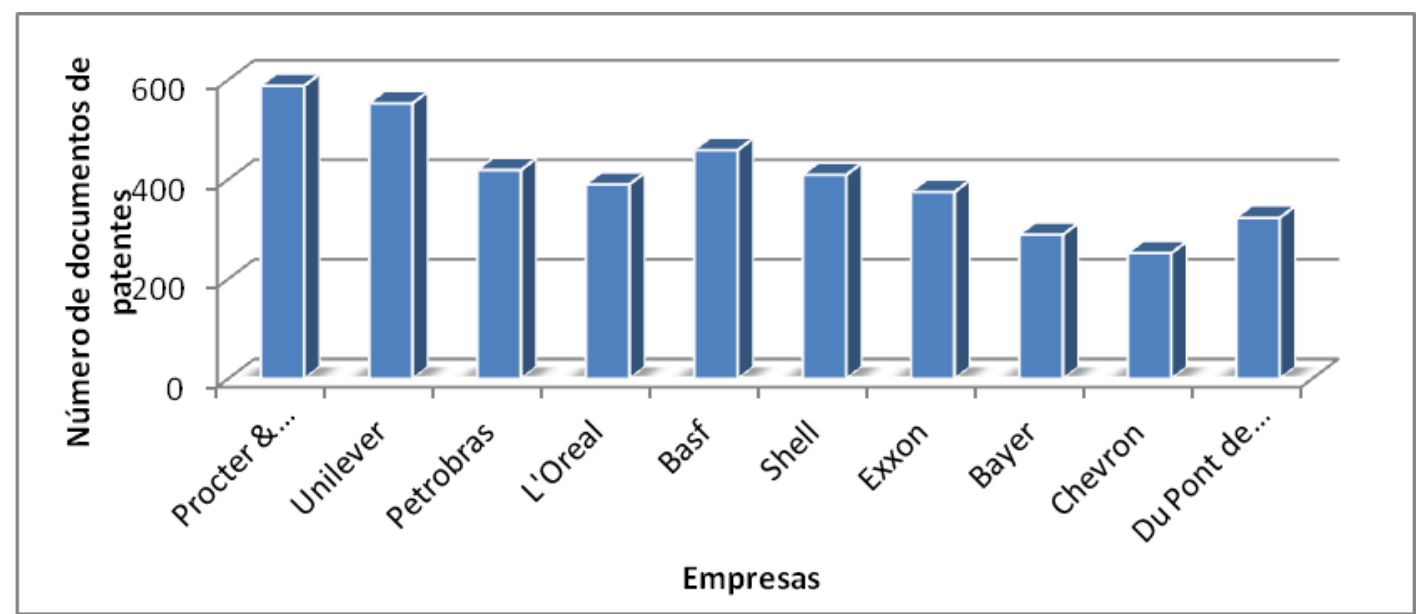

FIGURA 5. Número de depósito de patentes, por empresa, no período de 1994-2013.

Fonte: Elaborado pela autora

A partir da Figura 5 foi possível identificar que a empresa detentora do maior número de patentes depositadas na área petrolífera no Brasil é a Procter \& Gamble que é uma empresa americana, marca conhecida mundialmente por trabalhar com diversos produtos entre os quais produtos alimentícios, produtos de higiene e limpeza, dentre outros, onde a maior parte de sua produção é composta por matérias-primas derivadas do petróleo (PROCTER \& GAMBLE, 2014). A Unilever encontra-se em segundo lugar, sendo uma empresa Sul-africana, mas de origem holandesa, e bem conceituada no mercado mundial. A Unilever trabalha e desenvolve produtos em categorias como cuidados pessoais, alimentos, limpeza, refreshment (bebidas de soja e sorvetes) e alimentação fora do lar. Aqui no Brasil, o mercado nacional é atendido por 700 produtos de 25 marcas - entre elas, nomes consagrados como Omo, Comfort, Fofo, Seda, Lux, Dove, AdeS, Close Up e Rexona (UNILEVER, 2014). A Petrobras encontra-se na terceira colocação de empresas com maior número de depósito de documentos de patentes no Brasil. Ao analisar os documentos registrados pela Petrobras é possível verificar que muitos desses documentos de patentes estão voltados às atividades de pesquisa e desenvolvimento da empresa visando a política de qualidade de seus produtos e serviços. 
Nem sempre grandes investimentos geram lucros, mas para continuar no mercado as empresas precisam investir em novos conceitos e novos produtos. Inovar é necessário para ter um maior potencial de impacto dentro do mercado a partir do desenvolvimento de novas tecnologias. Porém, investir em novas tecnologias gera um valor agregado maior, e quanto maior este valor agregado na tecnologia, maior o potencial para o mercado atual, trazendo para a empresa uma possibilidade maior nas vendas em alta escala e maiores lucros.

\section{CONSIDERAÇÕES FINAIS}

Com o grande crescimento do mercado petrolífero há uma grande competitividade entre as empresas envolvidas, pois todas buscam através de suas inovações alcançarem maiores níveis de produção e produtividade, consequentemente gerando maiores oportunidades de trabalho. Existe também um grande avanço dessas empresas na área de inovação e tecnologia, com o intuito de melhorar a qualidade de seus produtos e também ter uma maior produção e espaço no ambiente competitivo internacional. Há sinalizações mostrando que os avanços tecnológicos nesta área estão aumentando, com a descoberta do Pré-sal e outros nichos em que o Brasil e também o mundo tem ainda como explorar e como efetivar mecanismos que levem a inovação.

O cenário petrolífero demonstra um avanço tecnológico nos últimos anos e com as descobertas de reservas petrolíferas recentes tanto no Brasil quanto em outros países a tendência é de que esta área se fortaleça implementando suas tecnologias e aumentando suas reservas. Assim, as empresas atuantes neste setor vêm se destacando cada vez mais no cenário mundial.

Ainda, destaca-se a importância que documentos de patentes têm para empresas que buscam conhecimentos, melhorias e inovações dentro de seus mercados, além da importância estratégica de se ter documentos de patentes como fonte de informações para possíveis subsídios futuros, melhorias de seus equipamentos e estudos, gerando sempre melhores oportunidades e garantia da concessão de exploração e exclusividade de seu invento.

\section{REFERÊNCIAS}

ABITANTE, K. G. Co-integração entre os mercados spot e futuro: evidências dos mercados de boi gordo e soja. Rev. Econ. Sociol. Rural. vol.46, n 1, p. 75-96, 2008.

ARAÚJO, E. F.; BARBOSA, C. M.; QUEIROGA, E S.; et al. Propriedade Intelectual: proteção e gestão estratégica do conhecimento. Revista Brasileira de Zootecnia, v.39, p.1$10,2010$.

BARBOSA, D. As 10 maiores petroleiras do mundo; Petrobras é a nona. Exame.com, 08 maio 2014. Disponível em: <http://exame.abril.com.br/negocios/noticias/as-10-maiorespetroleiras-do-mundo-Petrobras-e-a-nona/lista>. Acesso em: 10 nov.2014. 
BARBOSA, V. Os 15 países com as maiores reservas de petróleo do Mundo. Revista Exame: Negócios, 2012. Disponível em: <http://exame.abril.com.br/economia/noticias/os15-paises-com-a-maiores-reservas-de-petroleo-do-mundo\#1>. Acesso em: 14 maio 2014

BELL, M.; ROSS-LARSON, B.; WESTPHAL, L. E. Assessing the performance of infant industries. Journal of Development Economics, v.16, n.1-2, 1984. p.101-128. Disponível em: <http://ideas.repec.org/a/eee/deveco//v16y1984il-2p101-128.html >. Acesso em: 19 maio 2015.

BEZERRA, P. As 20 maiores empresas de petróleo segundo a.Forbes. Revista Exame: Negócios, 2013. Disponível em: <http://exame.abril.com.br/negocios/noticias/as-20-maioresempresas-de-petroleo-segundo-a-forbes\#1>. Acesso em: 12 maio 2014.

BRASIL. Lei n 9279, de 14 de maio de 1996. Regula direitos e obrigações relativos à propriedade industrial. Diário Oficial da União, Brasília, DF, 15 maio 1996. Disponível em: <http://www.planalto.gov.br/ccivil_03/Leis/L9279.htm>. Acesso em: 22 maio 2015.

DIRETÓRIO DE PATENTES. Importância do petróleo exige proteção do conhecimento. Propriedade Intelectual. Inovação Uniemp. vol.2, n.4, Campinas, 2006. p. 22-24. Disponível em: <http://inovacao.scielo.br/pdf/inov/v2n4/a13v02n4.pdf>. Acesso em: 25 fev. 2014.

EPSTEIN, G. Novas descobertas achatam preço do petróleo e mudam forças do mercado. 2014. The Wall Street Journal. Disponível em: <http://br.wsj.com/articles/SB10001424052702303987004579478063023311486>. Acesso em: 16 jun. 2014.

FUNDAÇÃO GETÚLIO VARGAS - FGV PROJETOS. O mercado do petróleo: oferta, refino e preço. A nova oferta do Petróleo. n. 15, 2012.

GASPARETTO JUNIOR, A. Crise do Petróleo. 2014. Disponível em: <http://www.infoescola.com/economia/crise-do-petroleo/>. Acesso em: 11 jul. 2014.

GOLDEMBERG, J.; LUCON, O. Energia e meio ambiente no Brasil. Estudos avançados, v. 21, n. 59, 2007. Disponível em: 〈http://www.scielo.br/pdf/ea/v21n59/a02v2159.pdf>. Acesso em: 27 fev. 2014.

GOUVEIA, F. Tecnologia nacional para extrair petróleo e gás do pré-sal. Agencia Iberoamericana para La difusión de La ciência y La tecnologia. Ciência Brasil. 2014. Disponível em: <http://www.dicyt.com/noticia/tecnologia-nacional-para-extrair-petroleo-egas-do-pre-sal>. Acesso em: 18 jul. 2014.

GUERRANTE, R. D. S. Estratégia de inovação e tecnologia em sementes. 270 f. Tese de 
doutorado (Doutorado). Universidade Federal do Rio de Janeiro, 2011. Disponível em: $<$ http://pt.scribd.com/doc/85219471/71/Analise-Qualitativa-do-Documento-de-Patente-US-6723-897-e-de-sua>. Acesso em: 28 Julho 2013.

INSTITUTO NACIONAL DE PROPRIEDADE INDUSTRIAL - INPI. Guia - Informação Tecnológica. 2014. Acesso em: 19 maio 2014. Disponível em: <http://www.inpi.gov.br/portal/artigo/guia_informacao_tecnologica>.

IPIRANGA. Nossa História. 2006. Disponível em: <http://www.ipiranga.com.br/grupo/>. Acesso em: 25 abr. 2014.

\section{LUSTOSA, M. C. J. Meio ambiente, inovação e competitividade na Indústria Brasileira:} a cadeia produtiva do petróleo. 245 f. 2002. Tese (Doutorado em Economia)-Instituto de Economia, Universidade Federal do Rio de Janeiro, Rio de Janeiro, 2002.

MARTINS, D. Ipiranga: a trajetória de uma refinaria em Rio Grande (RS) rumo à consolidação de um grupo empresarial (1930-1967). 2008. 140 f. Programa de pós-graduação (Dissertação de Mestrado)-Faculdade de filosofia e Ciências humanas. Pontifícia Universidade Católica do Rio Grande do Sul, 2008.

NIJHOF, E. Subject analysis and search strategies: has the searcher become the bottleneck in the search process. World Patent Information, Oxford, v. 29, n. 1, p. 20-25, 2007.

OCDE. Rumo a um desenvolvimento sustentável: indicadores ambientais. Paris: OCDE, 2002. p. 224. (Cadernos de referência ambiental, v. 9).

OPEC. OPEC share of Word crude oil reserves, 2013. 2013. Disponível em: <http://www.opec.org/opec_web/en/data_graphs/330.htm>. Acesso em: 10 mar. 2015. ORTIZ NETO, J. B.; COSTA, A. J. D. A Petrobras e a exploração de Petróleo Offshore no Brasil: um approach evolucionário. Rev. Bras. Economia, v. 61 n. 1, Rio de Janeiro, 2007, p. 95-109.

PEIXINHO, F. C. Proposta de aplicação do modelo de gestão estratégica baseado no "balanced scorecard - bsc" para uma empresa pública. Gerência Estratégica da Informação, 2003.

PETROBRAS. Tecnologia Petrobras 2012. Relatório de tecnologia Petrobras. 2013a.

PETROBRAS. Relatório de sustentabilidade 2013. 2013b Disponível em: <http://www.Petrobras.com.br/pt/sociedade-e-meio-ambiente/relatorio-de-sustentabilidade/>. Acesso em: 02 fev. 2015. 
PROCTER \& GAMBLE. História. Disponível em:

<http://www.pg.com/pt_BR/empresa/historia/index.shtml>. Acesso em: 02 fev. 2014.

RAO, I. K. Métodos quantitativos em biblioteconomia e ciência da informação. Brasília: ABDF, 1986.

ROSENBERG, N. Inside the Black Box: Technology and Economics, Londres: Cambridge University Press. 1982.

SANTOS, R. N. M. dos; KOBASHI, N. Y. Aspectos metodológicos da produção de indicadores em ciência e tecnologia. In: ENCONTRO NACIONAL DE CIÊNCIA DA INFORMAÇÃO, 6., 2005, Salvador. Anais... Salvador: Cinform, 2005.

SIMÕES, A. J. F. Petróleo, Gás Natural e Biocombustíveis: desafios estratégico no mundo e no Brasil. In: CONFERÊNCIA NACIONAL DEPOLÍTICA EXTERNA E POLÍTICA INTERNACIONAL. 1, 2006, Rio de Janeiro. O Brasil no mundo que vem aí. Brasília, DF: Fundação Alexandre de Gusmão, 2007. Disponível em: 〈http://pt.scribd.com/doc/86507696/ Conferencia-Nacional-de-Politica-Externa>. Acesso em 25 abr. 2014.

SOUZA, F. R. Impacto do preço do petróleo na política energética mundial. 2006. 160f. Dissertação (Mestrado em Ciências em Planejamento Energético)-Universidade Federal do Rio de Janeiro, Rio de Janeiro, 2006.

THOMAS, J. E. Fundamentos de Engenharia de Petróleo, $2^{\text {a }}$ edição, Rio de janeiro: Editora Iterciência, 2001. 271 p.

UNILEVER. Sobre a Unilever. Disponível em:

<http://www.unilever.com.br/aboutus/aboutunilever/> . Acesso em: 02 fev. 2015.

ZHU, D. et al. A process for mining science \& technology documents databases illustred for the case of knowledge discovery and data mining. Ciência da Informação, Brasília, DF, v. 28, n.1, jan. 1999. 
SCHIAVI, Marcela Taiane. Cenário petrolífero: sua evolução, principais produtores e tecnologias. Revista Digital de Biblioteconomia e Ciência da Informação, Campinas, SP, v. 13, n. 2, p. 259-278, maio/ago. 2015. ISSN 1678-765X. Disponível em: $<$ http://periodicos.bc.unicamp.br/ojs/index.php/rdbci/article/view/2104>. Acesso em: 31 maio 2015. 